\title{
CATALYTIC CRACKING OF PALM OIL OVER ZEOLITE CATALYSTS: STATISTICAL APPROACH
}

\author{
F. A. A. Twaiq and S. Bhatia* \\ School of Chemical Engineering, Universiti Sains Malaysia, Engineering Campus, 14300 Nebong Tebal, SPS, \\ Pinang. \\ chbhatia@eng.usm.my
}

\section{N. A. M. Zabidi}

Department of Chemical Engineering, Universiti Technologi Petronas, Sri Iskandar 31750 Tronoh, Perak.

\begin{abstract}
The catalytic cracking of palm oil was conducted in a fixed bed micro-reactor over HZSM-5, zeolite $\beta$ and ultrastable Y (USY) zeolite catalysts. The objective of the present investigation was to study the effect of cracking reaction variables such as temperature, weight hourly space velocity, catalyst pore size and type of palm oil feed of different molecular weight on the conversion, yield of hydrocarbons in gasoline boiling range and BTX aromatics in the organic liquid product. Statistical Design of Experiment (DOE) with $2^{4}$ full factorial design was used in experimentation at the first stage. The nonlinear model and Response Surface Methodology (RSM) were utilized in the second stage of experimentation to obtain the optimum values of the variables for maximum yields of hydrocarbons in gasoline boiling range and aromatics. The HZSM-5 showed the best performance amongst the three catalysts tested. At $623 \mathrm{~K}$ and WHSV of $1 \mathrm{~h}^{-1}$, the highest experimental yields of gasoline and aromatics were 28.3 wt. $\%$ and 27 wt.\%, respectively over the HZSM-5 catalyst. For the same catalyst, the statistical model predicted that the optimum yield of gasoline was 28.1 wt.\% at WHSV of $1.75 \mathrm{~h}^{-1}$ and $623 \mathrm{~K}$. The predicted optimum yield of gasoline was $25.5 \mathrm{wt} \%$ at $623 \mathrm{~K}$ and WHSV of $1 \mathrm{~h}^{-1}$.
\end{abstract}

KEY WORDS: Catalytic Cracking, Palm Oil, Zeolite, Design Of Experiment, Response Surface Methodology.

\section{INTRODUCTION}

The technology of catalytic cracking of triglycerides to produce fuels and other chemicals was investigated to find new sources of energy from plant oils ${ }^{[1]}$. Canola oil, tall oil, jajoba oil, and other types of plant oils were converted to several types of hydrocarbons by HZSM-5, Hydrogen-zeolite Y, Silica-alumina, H-Mordenite and Silica alumina-pillared clay catalysts, in the temperature range of $573-773 \mathrm{~K}^{[2]}$. Direct upgrading of plant oils to fuels and chemicals could be of great help in local over production, and low international prices of agro products or higher prices of fossil fuels in isolated areas. Shape selective zeolite catalysts can be used for converting palm oil to premium transportation fuels $\mathrm{s}^{[3]}$. The shape selective zeolite catalyst used for catalytic cracking of canola oil was able to convert $60-95$ wt.\% of this oil to hydrocarbons in gasoline boiling range and light gases ${ }^{[4]}$. It has been reported that HZSM-5 gave mainly aromatic hydrocarbons from canola oil ${ }^{[5]}$. The properties of shape selective catalysts control the product distribution in the process, therefore, the choice of shape selective zeolite catalyst is an important factor $^{[4]}$. Activity and selectivity of these catalysts are governed by several factors such as acidity, pore size and distribution ${ }^{[2]}$. The conversion of palm oil to hydrocarbons in fuel range over different zeolite catalysts has been investigated by Bhatia et al. ${ }^{[3]}$. The zeolites studied were HY, H-beta and HZSM-5. They have different characteristics, and are highly acidic cracking catalysts, the main difference was in the pore size dimensions ${ }^{[6]}$.

Statistical design of experiments were applied in the catalytic conversion of vegetable oils to fuel ${ }^{[5]}$. It was used to study the effects of operating conditions such as temperature, WHSV and catalyst properties that have significant effects on the yield of selected products such as gasoline and aromatic hydrocarbons ${ }^{[7]}$. It has been reported that the type of catalyst, temperature and WHSV are some of the main variables that affect the conversion and production of hydrocarbons in the gasoline boiling range ${ }^{[8]}$.

The statistical model arises when the information available concerning a random process or system does not fully determine the probability model. The statistical model is typically taken to be the set of possible probability models. A mathematical linear model for conversion and yield of products can be obtained from the $2^{\mathrm{k}}$ factorial design. A model will describe the relation between the independent variables and the conversion of palm oil, gasoline and aromatics production. The models can predict the yields of product in terms of the significant variables in the process. These variables may be significant in one level of experimentation but negligible in another level as shown in the empirical model obtained from the design of experiment study ${ }^{[9]}$. The analysis of variance (ANOVA) table partitions the total sample variability in an experimental design into components attributable to specific independent variables and interaction between independent variables ${ }^{[10]}$. 
The non-linear model is required when curvature is found in the linear model to apply response surface method $^{[11]}$. Response surface methodology is closely related to univariate experimental design and it has broad applications in industrial statistics. Response surface designs are usually used to justify a local linear approximation to the unknown function, then draw observation, and fit linear regression models of the desired responses to enable influence on the direction of steepest ascent ${ }^{[12]}$. To obtain the curvature effects, it would be necessary to consider an experimental design which would allow one to fit the experimental data to a nonlinear model ${ }^{[13]}$. When the vicinity of the maximum has been reached, the linearity in the model is enlarged to exclude quadratic and cross product terms, enabling estimation of the optimal location.

The objectives of the present research are; (a) to study the effects of cracking reaction conditions on the conversion of palm oil to hydrocarbon products in the gasoline boiling point range; (b) to optimize the cracking reaction variables such as reaction temperature, weight hourly space velocity (WHSV), pore size of zeolite catalyst and the feed molecular weight for higher production of hydrocarbons in the gasoline range and the aromatic hydrocarbons contents.

\section{EXPERIMENTAL}

\subsection{Chemicals and Catalysts}

Two types of palm oil were used in the present investigation, refined, bleached and deodorized (RBD) palm olein and palm kernel oil, they were obtained from M/S Golden agriculture oils Sdn. Bhd., Butterworth Penang, Malaysia, and M/S Acidchem International Sdn. Bhd., Butterworth - Penang, Malaysia, respectively. The chemical properties of the Malaysian palm olein as fatty acid composition \% (as methyl ester) was C12:0, 0.27; C14:0, 1.09; C16:0, 40.93; C18:0, 4.18; C18:1, 41.51; C18:2, 11.64; C18:3, 0.40; C20:0, 0.37 and palm kernel oil C6, 0.30; C8, 4.20; C10, 3.70; C12:0, 48.70; C14:0, 15.60; C16:0, 7.50; C18:0, 1.80; C18:1, 14.80; C18:2, 2.60; C18:3, $0.10{ }^{[14]}$. Argon of 99.99\% purity was obtained from Malaysian Oxygen Sdn. Bhd., Kuala Lumpur and was used in the cracking of palm oil as a purge gas. Three zeolite catalysts HZSM-5, zeolite $\beta$ and USY of different pore size were used. The HZSM-5 zeolite (CBU 8070) and zeolite $\beta$ (811BL-25) were supplied by P.Q. Corporation, Kansas, USA. The ultrastable Y (USY) zeolite was obtained from W. R. Grace (s) Ltd., Grace Division, Asia Pacific, Singapore. The three zeolites were in powder form with particle size $<32 \mu \mathrm{m}$. The HZSM-5 and USY zeolites were calcined in a muffle furnace for $6 \mathrm{~h}$ at $773 \mathrm{~K}$ and zeolite $\beta$ was calcined at $673 \mathrm{~K}$ prior to use. The properties of the catalysts are presented in Table 1 .
Table 1: Chemical and physical characteristics of the zeolite

\begin{tabular}{ccccc}
\hline Catalyst & Si/Al ratio & $\begin{array}{c}\text { Pore size } \\
(\mathrm{nm})\end{array}$ & $\begin{array}{c}\text { BET } \\
\text { surface } \\
\text { area } \\
\left(\mathrm{m}^{2} / \mathrm{g}\right)\end{array}$ & $\begin{array}{c}\text { Acidity } \\
(\mathrm{mmol} \\
\left.\mathrm{NH}_{3}\right)\end{array}$ \\
\hline HZSM-5 & 50 & $0.54 \times 0.56$ & 390 & 0.55 \\
$\begin{array}{c}\text { Zeolite } \beta \\
\text { Ultra } \\
\text { stable Y }\end{array}$ & 14 & $0.56 \times 0.74$ & 410 & 1.1 \\
\hline
\end{tabular}

\subsection{Procedure}

Experiments were conducted in a stainless steel microreactor $(155 \mathrm{~mm} \times 10 \mathrm{~mm}$ I.D. $)$ fitted with a thermocouple fixed in the center of the catalyst bed[3]. One gram of calcined powder catalyst was loaded over $0.2 \mathrm{~g}$ of quartz wool then covered with quartz wool and placed into the micro-reactor. The reactor was heated to the desired reaction temperature using an electrical vertical tube furnace. Argon gas was allowed to flow at $0.2 \mathrm{l} / \mathrm{h}$ through the system for $1 \mathrm{~h}$ before feeding the palm oil into the reactor. The palm oil was fed by a syringe metering pump (Cole-Parmer) and was preheated to 573 $\mathrm{K}$ in a horizontal tube furnace to the reactor.

The products were cooled by circulated water at 313 $\mathrm{K}$ in a condenser. The liquid products were collected in a glass sampler trap and the gaseous products separated in the trap were collected in a Teflon sampling bag. The aqueous phase product was separated from the liquid product using a syringe. In order to estimate the quantity of the residual oil, the liquid product was distilled in a micro-distillation unit (Buchi B580, GKR) at a temperature of $473 \mathrm{~K}$ under a vacuum of $5 \mathrm{~Pa}$. The distillate fraction was the organic liquid product (OLP) and the pitch was the residual oil.

\subsection{Analysis of Products}

The gaseous products were analyzed with a gas chromatograph (Hewlett Packard, model No. 5890 series II) using a Porapak Q stainless steel column (90m-length $\times 3.15 \mathrm{~mm}$ I.D.). The GC was equipped with both flame ionization detector (FID) and thermal conductivity detector (TCD). The analysis time was approximately $30 \mathrm{~min}$ for each injection. After normalizing the components, main molecular weight for the gases were calculated to determine the weight of the gaseous products. The FID was used to analyze the organic liquid products (OLP) using a capillary glass column (Petrocol DH 50.2, film thickness $0.5 \mu \mathrm{m}, 50 \mathrm{~m}$ length and $0.2 \mathrm{~mm}$ I.D.).

The chromatogram was obtained for $90 \mathrm{~min}$. The components were defined according to petroleum fuel boiling point ranges by injecting commercial samples of gasoline, kerosene, diesel and pure benzene, toluene and xylene. The spent catalyst was washed with hexane to determine the remaining residual oil over the catalyst. The coke formed on the catalyst during the cracking reaction was determined using a thermal gravimetric analyzer (Perkin-Elmer TGA7). 


\section{RESULTS AND DISCUSSION}

A fundamental part of statistics is concerned with the design of experiments to determine cause-effect relationship; the relationship with some response of the system is very important. For solving problem by statistical methods, a plan of the experiment must be set up that includes the method of collecting the data, the size of the sample and the method to solve the problem $^{[12]}$. The full factorial design was used in the present investigation to assess the effect of the reaction parameters such as reaction temperature (T), weight hourly space velocity (WHSV), zeolite catalyst pore size (CPS) and feed molecular weight as the number of carbon atoms in the triglyceride molecule (NCA) on the conversion of palm oil $\left(P_{C}\right)$, yield of hydrocarbons in gasoline boiling range $\left(Y_{G}\right)$ and $\mathrm{BTX}$ aromatic hydrocarbons $\left(Y_{A}\right)$ in the liquid product. The conversion and yield of the desired product are defined as follows:

Conversion $(\mathrm{wt} . \%)=$

$\frac{\mathfrak{a G a s}+\text { OLP }+ \text { Water }+ \text { Coke } \frac{\ddot{o}}{\dot{\bar{\phi}}}}{\text { Palm oil feed }} 100 \%$
Yield of desired product (wt.\%) =

$\underset{\text { Palm oil feed }}{\text { Paired product }} \frac{\ddot{\bar{\phi}}}{\dot{\bar{\phi}}} 100 \%$

\subsection{Linear Model}

The classical linear model in statistics assumes that observations are linearly related to the explanatory variables and are measured with independent, normal distributed error. The factorial design allows for examination of all main effects of the factors at any level and interactions between these factors ${ }^{[15]}$. The selection of the parameter intervals was based on the best operating conditions reported in the literature ${ }^{[8]}$ and are presented in Table 2 . The $2^{4}$ full factorial design was used in the first experimentation stage; with two levels for each factor. The experimental matrix for the sixteen experiments is shown in Table 3. The significant variables and their effects on the responses have to be identified in order to study the effects of the reaction variables on the palm oil conversion $\left(P_{C}\right)$, yield of hydrocarbons in the gasoline boiling range $\left(Y_{G}\right)$ and the yield of BTX aromatic hydrocarbons $\left(Y_{A}\right)$. In addition, one must also determines whether the interactions of these variables affect the responses.

Table 2: Independent variables coded and real values used in the linear model

\begin{tabular}{ccccc}
\hline Factor & Temperature (T) & $\begin{array}{c}\text { Weight hourly space } \\
\text { velocity (WHSV) }\end{array}$ & $\begin{array}{c}\text { Catalyst pore size } \\
\text { (CPS) }\end{array}$ & $\begin{array}{c}\text { Number of carbon atoms } \\
\text { in the feed (NCA) }\end{array}$ \\
\hline Factor code & $\mathrm{A}$ & $\mathrm{B}$ & $\mathrm{C}$ & $\mathrm{D}$ \\
Unit & $\mathrm{K}$ & $\mathrm{h}^{-1}$ & $\mathrm{~nm}$ & - \\
Intervals & $623-723$ & $1-4$ & $0.54-0.80$ & $38.5-51.0$ \\
\hline
\end{tabular}

Table 3: Experimental matrix of the $2^{4}$ factorial design

\begin{tabular}{|c|c|c|c|c|c|c|c|}
\hline $\mathrm{T}$ & WHSV & CPS & NCA & Treatment combination & $\mathrm{P}_{\mathrm{C}}$, wt. $\%$ & $\mathrm{Y}_{\mathrm{G}}$, wt.\% & $\mathrm{Y}_{\mathrm{A}}$, wt.\% \\
\hline 623 & 1 & 0.54 & 38.5 & 1 & 98.89 & 29.25 & 26.64 \\
\hline 723 & 4 & 0.80 & 51.0 & $\mathrm{ABCD}$ & 57.61 & 11.68 & 1.79 \\
\hline 723 & 1 & 0.80 & 51.0 & $\mathrm{ACD}$ & 93.16 & 17.52 & 5.16 \\
\hline 723 & 4 & 0.54 & 38.5 & $\mathrm{AB}$ & 83.73 & 19.53 & 15.51 \\
\hline 723 & 1 & 0.80 & 38.5 & $\mathrm{AC}$ & 93.76 & 18.10 & 4.19 \\
\hline 723 & 4 & 0.54 & 51.0 & $\mathrm{ABD}$ & 86.05 & 24.40 & 20.29 \\
\hline 623 & 1 & 0.54 & 51.0 & $\mathrm{D}$ & 99.01 & 28.29 & 27.06 \\
\hline 723 & 4 & 0.80 & 38.5 & $\mathrm{ABC}$ & 56.60 & 7.21 & 2.40 \\
\hline 623 & 4 & 0.80 & 38.5 & $\mathrm{BC}$ & 28.65 & 1.64 & 1.10 \\
\hline 623 & 4 & 0.80 & 51.0 & $\mathrm{BCD}$ & 28.34 & 3.83 & 1.73 \\
\hline 723 & 1 & 0.54 & 51.0 & $\mathrm{AD}$ & 97.23 & 24.15 & 18.19 \\
\hline 623 & 1 & 0.80 & 38.5 & $\mathrm{C}$ & 60.21 & 7.96 & 1.79 \\
\hline 623 & 1 & 0.80 & 51.0 & $\mathrm{CD}$ & 53.20 & 7.33 & 2.16 \\
\hline 723 & 1 & 0.54 & 38.5 & A & 98.33 & 22.48 & 19.23 \\
\hline 623 & 4 & 0.54 & 51.0 & $\mathrm{BD}$ & 77.35 & 23.48 & 16.70 \\
\hline 623 & 1 & 0.54 & 51.0 & $\mathrm{D}$ & 79.13 & 22.05 & 19.17 \\
\hline
\end{tabular}

The four independent variables identified for this study were coded as T (A), WHSV (B), CPS (C) and NCA (D). Each variable is presented at two levels, the low level (-1) and the high level $(+1)$. The sixteen experiments were performed in a random manner to minimize personal bias. Figures 1,2 and 3 present the normal probability plot for $P_{C}, Y_{G}$ and $Y_{A}$ versus the estimated effect, respectively. Based on this plot, all the effects that lie along the line are considered negligible; whereas the large effects are those which are far from the line.

Tables 4, 5 and 6 show the analysis of variance (ANOVA) for the three responses, $P_{C}, Y_{G}$ and $Y_{A}$, 
respectively. Column 1 in these tables presents the main factors and its interactions and column 2 presents the estimated effect for each factor or interaction. The sum of squares presented in column 3 was calculated from the sum of squares of the significant factors and its interactions. The $F$-values are tabulated in column 6 and were compared to the critical $F$-values. The critical $F$ values are shown in column 6 of table 6 as superscript values. The $F$-critical values were obtained from the percentage points tables of the $F$ - distribution at $1 \%$ level reported in ref. [15]. Regression analysis for the data was obtained from the factorial runs using the Design-Expert software (version 5.0). The coefficients for all the effects were obtained for $P_{C}, Y_{G}$ and $Y_{A}$ and are presented in column 5. The ANOVA shows that the linear model is significant for all the responses.

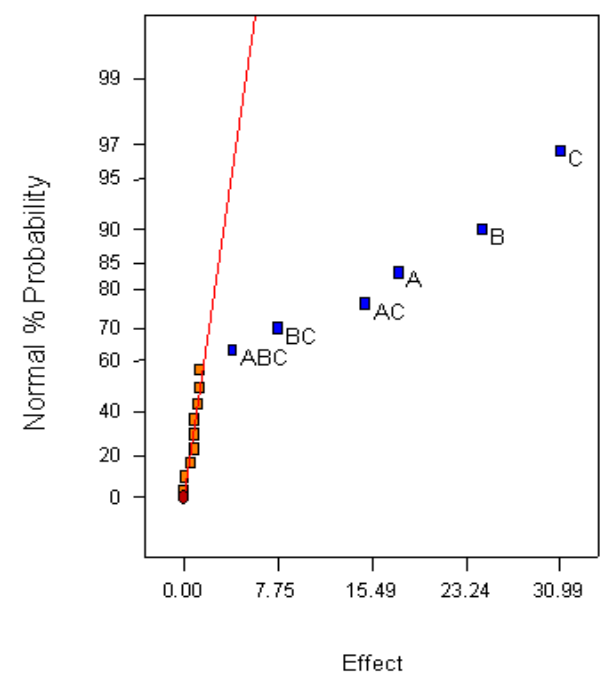

Fig. 1: Normal probability plot of effects for the 24 factorial design for conversion of palm oil.

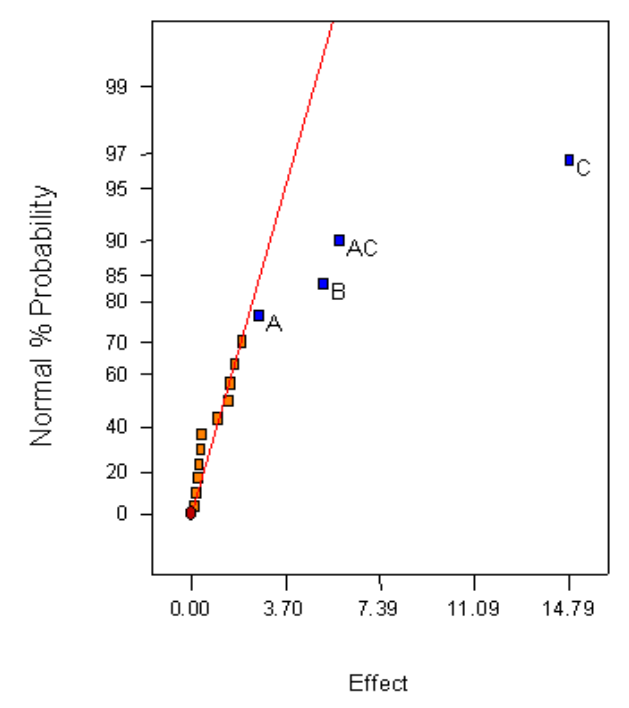

Fig. 2: Normal probability plot of effects for the 24 factorial design for yield of gasoline.

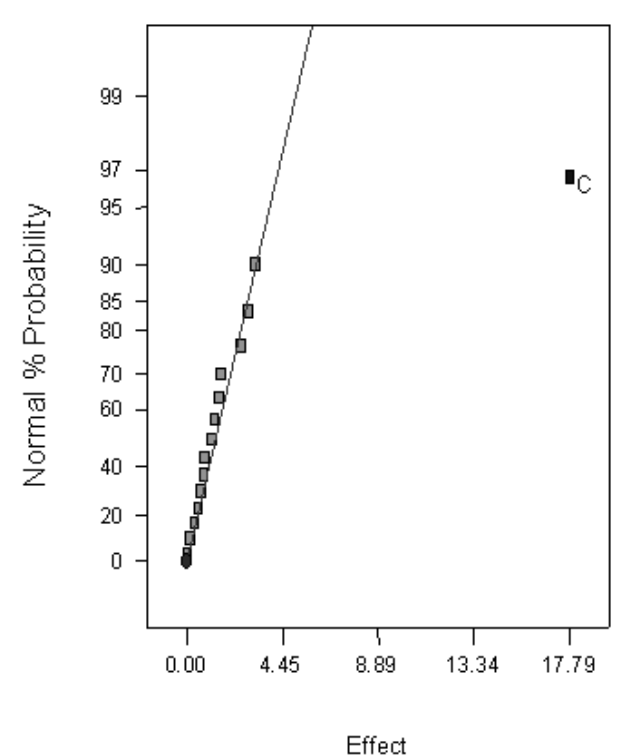

Fig. 3: Normal probability plot of effects for the $2^{4}$ factorial design for yield of aromatics

\subsubsection{Influence of reaction variables on the responses}

Factor D (feed molecular weight) and its interactions have no significant effect on the three responses, so it was neglected from the design. It was found that the conversion at different WHSV's and temperatures was almost identical with both types of feed. This result is in line with the reported results for the cracking of linear paraffins, in which conversion was constant when the carbon atoms in the chain were more than 25 for the linear hydrocarbons and greater than 35 for the nonlinear hydrocarbons ${ }^{[16]}$.

Palm oil conversion $\left(\mathrm{P}_{\mathrm{C}}\right)$ : The effect of reaction temperature on the palm oil conversion was positive. The WHSV has a negative effect on the conversion of palm oil in which the conversion decreased with increase in WHSV. The CPS also shows a negative effect on the conversion. It was observed that palm oil conversion did not increase with the increase of temperature over HZSM-5 catalyst having average pore size opening of $0.54 \mathrm{~nm}$ at the low level of WHSV. The results are in line with the reported data for canola oil cracking $^{[7]}$. The statistical model was applied to study the effect of WHSV and temperature on the organic liquid products with different acid catalysts ${ }^{[7]}$. The selectivity of aromatics from canola oil was inline to those obtained from palm oil. This result indicates no real effect of the main factor itself, however there were significant effects on the interactions. The effect of the main factors should be neglected because the main factor has a positive effect on one level and negative effect at another level. In Table 4, it is clear that the interaction $\mathrm{AC}$ has a positive effect, whereas the $\mathrm{C}$ factor has a negative effect. The $F$-value for the model was found to be significant at $1 \%$ level. 
Table 4: Analysis of variance (ANOVA) for conversion

\begin{tabular}{ccccccc}
\hline $\begin{array}{c}\text { Source of } \\
\text { variance }\end{array}$ & $\begin{array}{c}\text { Estimated } \\
\text { Effect }\end{array}$ & $\begin{array}{c}\text { Sum of } \\
\text { squares }\end{array}$ & $\begin{array}{c}\text { Degree of } \\
\text { freedom }\end{array}$ & $\begin{array}{c}\text { Model } \\
\text { coefficient }\end{array}$ & $\boldsymbol{F}$-VALUE & \% Contribution \\
\hline Intercept & - & - & - & 74.44 & - & - \\
A & 17.71 & 1254.93 & 1 & 8.85 & $41.60^{11.26}$ & 14.35 \\
B & -24.56 & 2413.27 & 1 & -12.28 & $80.10^{11.26}$ & 27.66 \\
C & -30.98 & 3840.90 & 1 & -15.49 & $127.50^{11.26}$ & 43.93 \\
D & -0.93 & 3.51 & 1 & -0.46 & $0.11^{11.26}$ & 0.04 \\
AB & -0.08 & 0.03 & 1 & -0.04 & $0.00^{11.26}$ & 0.00 \\
AC & 14.98 & 898.50 & 1 & 7.49 & $29.80^{11.26}$ & 10.27 \\
AD & 1.33 & 7.15 & 1 & 0.66 & $0.23^{11.26}$ & 0.08 \\
BC & -7.73 & 239.47 & 1 & -3.86 & $7.95^{11.26}$ & 2.73 \\
BD & 1.21 & 5.88 & 1 & 0.60 & $0.20^{11.26}$ & 0.06 \\
CD & -0.81 & 2.64 & 1 & -0.40 & $0.09^{11.26}$ & 0.03 \\
ABC & -4.01 & 64.40 & 1 & -2.00 & $0.09^{11.26}$ & 0.73 \\
ABD & 0.03 & 0.00 & 1 & 0.01 & $0.00^{11.26}$ & 6.43 \\
ACD & 0.61 & 1.50 & 1 & 0.30 & $0.05^{11.26}$ & 0.01 \\
BCD & 0.83 & 2.80 & 1 & 0.41 & $0.09^{11.26}$ & 0.03 \\
ABCD & -1.28 & 6.63 & 1 & -0.64 & $0.22^{11.26}$ & 0.07 \\
Model & - & 8711.50 & 7 & - & $26.711^{6.18}$ & - \\
Residuals & - & 30.13 & 8 & - & - & - \\
\hline Note: the critical $F$-values are shown as superscript in column 6. & & &
\end{tabular}

Table 5: Analysis of variance (ANOVA) for gasoline yield

\begin{tabular}{ccccccc}
\hline $\begin{array}{c}\text { Source of } \\
\text { variance }\end{array}$ & $\begin{array}{c}\text { Estimated } \\
\text { Effect }\end{array}$ & $\begin{array}{c}\text { Sum of } \\
\text { squares }\end{array}$ & $\begin{array}{c}\text { Degree of } \\
\text { freedom }\end{array}$ & Model coefficient & $F$-value & \% Contribution \\
\hline Intercept & & & 1 & & - & \\
A & 1.33 & 2.66 & 1 & 28.35 & $5.90^{9.65}$ & 2.3 \\
B & -2.58 & -5.16 & 1 & 106.60 & $22.00^{9.65}$ & 8.9 \\
C & -7.39 & -14.78 & 1 & 874.68 & $181.00^{9.65}$ & 73.0 \\
D & 0.78 & 1.56 & 1 & 9.76 & $2.00^{9.65}$ & 0.8 \\
AB & 0.15 & 0.31 & 1 & 0.39 & $0.08^{9.65}$ & 0.0 \\
AC & 2.89 & 5.78 & 1 & 133.98 & $27.80^{9.65}$ & 11.1 \\
AD & 0.51 & 1.03 & 1 & 4.30 & $0.90^{9.65}$ & 0.3 \\
BC & -0.74 & -1.48 & 1 & 8.85 & $1.80^{9.65}$ & 0.7 \\
BD & 0.85 & 1.71 & 1 & 11.73 & $2.40^{9.65}$ & 0.9 \\
CD & -0.10 & -0.21 & 1 & 0.18 & $0.04^{9.65}$ & 0.0 \\
ABC & -1.00 & -2.01 & 1 & 16.20 & $3.30^{9.65}$ & 1.3 \\
ABD & 0.19 & 0.38 & 1 & 0.60 & $0.12^{9.65}$ & 0.0 \\
ACD & -0.21 & -0.43 & 1 & 0.76 & $0.12^{9.65}$ & 0.0 \\
BCD & 0.14 & 0.28 & 1 & 0.33 & $0.07^{9.65}$ & 0.0 \\
ABCD & 0.08 & 0.16 & 1 & 0.10 & $0.02^{9.65}$ & 0.0 \\
Model & & 1143.62 & 4 & - & $59.15^{5.67}$ & \\
Residuals & & 53.23 & 11 & & & \\
\hline Note: the critical $F$-values are shown as superscript in column 6. & & & & \\
& & & & & & \\
\end{tabular}


Table 6: Analysis of variance (ANOVA) for aromatics yield

\begin{tabular}{ccccccc}
\hline $\begin{array}{c}\text { Source of } \\
\text { variance }\end{array}$ & Estimated Effect & $\begin{array}{c}\text { Sum of } \\
\text { squares }\end{array}$ & $\begin{array}{c}\text { Degree of } \\
\text { freedom }\end{array}$ & Model coefficient & F-value & \% Contribution \\
\hline $\begin{array}{c}\text { Intercept } \\
\text { A }\end{array}$ & -1.18 & 5.64 & 1 & -0.59 & $0.56^{8.86}$ & 0.40 \\
B & -3.21 & 41.28 & 1 & -1.60 & $4.12^{8.86}$ & 2.93 \\
C & -17.78 & 1265.58 & 1 & -8.89 & $126.50^{8.86}$ & 89.96 \\
D & 0.38 & 0.60 & 1 & 0.19 & $0.06^{8.86}$ & 0.04 \\
AB & 1.51 & 9.15 & 1 & 0.75 & $0.90^{8.86}$ & 0.65 \\
AC & 2.88 & 33.35 & 1 & 1.44 & $3.30^{8.86}$ & 2.37 \\
AD & 0.66 & 1.75 & 1 & 0.33 & $0.17^{8.86}$ & 0.12 \\
BC & 1.61 & 10.40 & 1 & 0.80 & $1.00^{8.86}$ & 0.73 \\
BD & 0.18 & 0.14 & 1 & 0.09 & $0.00^{8.86}$ & 0.00 \\
CD & -0.03 & 0.00 & 1 & -0.02 & $0.00^{8.86}$ & 0.00 \\
ABC & -2.51 & 25.25 & 1 & -1.25 & $2.50^{8.86}$ & 1.79 \\
ABD & 0.86 & 2.97 & 1 & 0.43 & $3.00^{8.86}$ & 0.21 \\
ACD & -0.81 & 2.64 & 1 & -0.40 & $2.60^{8.86}$ & 0.18 \\
BCD & -0.53 & 1.15 & 1 & -0.26 & $0.10^{8.86}$ & 0.08 \\
ABCD & -1.31 & 6.89 & 1 & -0.65 & $6.80^{8.86}$ & 0.48 \\
Model & & 1265.58 & 1 & & $10.32^{8.86}$ & \\
Residuals & & 141.24 & 14 & & & \\
\hline
\end{tabular}

Note: the critical $F$-values are shown as superscript in column 6 .

Yield of hydrocarbons in gasoline boiling range $\left(\mathrm{Y}_{\mathrm{G}}\right)$ : The reaction temperature has a low positive contribution on the production of hydrocarbons in the gasoline range and WHSV has a negative effect on the yield of hydrocarbons. The pore size of the zeolite catalyst is the most important factor in the palm oil cracking process. The pore size of the zeolite has a large negative contribution on the $Y_{G}$. It is reported that the catalyst and WHSV are the factors which control the production of the liquid products and reaction temperature has no effect on the selectivity of aliphatic hydrocarbons ${ }^{[7]}$. The values of $Y_{G}$ decreased with increase of reaction temperature over HZSM-5 catalyst which indicates over-cracking. With large pore zeolite USY $(0.8 \mathrm{~nm}), Y_{G}$ increased with increase of reaction temperature. This result is related to the significant effect of the interaction of AC which caused the HZSM5 catalyst to give higher $Y_{G}$ at low temperature level, and the USY zeolite to give higher $Y_{G}$ at high temperature level. The $F$-value for the model was found to be significant at $1 \%$ level and the linear model can predict the values for $Y_{G}$.

Yield of BTX aromatics $\left(\mathrm{Y}_{\mathrm{A}}\right)$ : The reaction temperature and WHSV and their interactions have no significant contribution to the yield of aromatics compared to that of the catalyst pore size. Catalyst pore size (CPS) of the zeolite was the only factor contributing to $Y_{A}$. The medium pore size presented in HZSM-5 zeolite shows the role of the pore dimension on the selectivity of the catalyst as selective for aromatic hydrocarbons. The role of the shape selectivity is obvious where the effect of reaction temperature is very little compared to the effect of the shape selectivity of the catalyst. The medium pore zeolite HZSM-5 was reported as selective for aromatics in the cracking of gas oil. HZSM-5 catalyst has been used as additive on FCC unit to improve the octane number of the gasoline ${ }^{[17]}$. In the literature, it is reported that addition of HZSM-5 catalyst used in the canola oil cracking combined with reaction temperature influenced the production of aromatic hydrocarbons in the process [7]. The selectivity of the catalyst is affected by variables such as the acidity of the catalyst and the shape of catalyst pore as well the location of the active sites in side the pores. The $F$-value for the model was found to be significant at $1 \%$ level.

\subsection{Nonlinear Model}

To optimize the cracking reaction variables in the study range for greater $Y_{G}$ and $Y_{A}$, higher polynomial degree model was required and response surface methodology (RSM) was used. To apply this model, an additional central level was added to the significant factors ( $T$, WHSV and CPS) in the design to be a $3^{3}$ full factorial design as shown in Table 7. The low level was coded as 0 , central level as 1 and the high level as 2 for each factor. Zeolite $\beta$ catalyst (pore size $0.56 \times 0.74 \mathrm{~nm}$ ) was used as the central level for the catalyst pore size factor in further experimentation. The total number of experiments was 27 and five repeated runs were performed at $673 \mathrm{~K}$ and $2.5 \mathrm{~h}^{-1}$ using zeolite $\beta$ catalyst in order to estimate the experimental error. The experimental error was used to calculate the lack of fit test. The results of these experiments are presented in Table 8 . The analysis of variance (ANOVA) for the $3^{3}$ design is tabulated in Table 9. The residual sum of squares was used to calculate the $F$-values. The $F$ values for the models obtained from ANOVA for the three responses are significant at $1 \%$ level. The Design-Expert software was used to estimate the final quadratic equation for the three responses in terms of actual values of the factors. Eqs. 3, 4 and 5 present the statistical quadratic models estimated from the significant effects and its interactions. 
Table 7: Independent variables coded and real values used in the nonlinear model

\begin{tabular}{cccccc}
\hline Factor & $\begin{array}{c}\text { Factor } \\
\text { code }\end{array}$ & Unit & $\begin{array}{c}\text { Low } \\
\text { level } \\
(0)\end{array}$ & $\begin{array}{c}\text { Center } \\
\text { level } \\
(1)\end{array}$ & $\begin{array}{c}\text { High } \\
\text { level } \\
(2)\end{array}$ \\
\hline $\mathrm{T}$ & $\mathrm{A}$ & $\mathrm{K}$ & 623 & 673 & 723 \\
WHSV & $\mathrm{B}$ & $\mathrm{h}^{-1}$ & 1 & 2.5 & 4 \\
$\mathrm{CPS}$ & $\mathrm{C}$ & $\mathrm{nm}$ & 0.54 & 0.67 & 0.80 \\
\hline
\end{tabular}

Table 8: Experimental matrix of the $3^{3}$ factorial design

\begin{tabular}{|c|c|c|c|c|c|c|}
\hline $\begin{array}{c}\mathrm{T} \\
(\mathrm{K})\end{array}$ & $\begin{array}{c}\text { WHSV } \\
\left(\mathrm{h}^{-1}\right)\end{array}$ & $\begin{array}{l}\text { CPS } \\
(\mathrm{nm})\end{array}$ & $\begin{array}{c}\text { Treatment } \\
\text { combination }\end{array}$ & $\mathrm{P}_{\mathrm{C}}$ & $\mathrm{Y}_{\mathrm{G}}$ & $\overline{Y_{A}}$ \\
\hline 623 & 1.0 & 0.54 & 000 & 99.0 & 28.3 & 27.0 \\
\hline 623 & 1.0 & 0.67 & 001 & 82.2 & 22.0 & 3.5 \\
\hline 623 & 1.0 & 0.80 & 002 & 53.2 & 7.3 & 2.2 \\
\hline 623 & 2.5 & 0.54 & 010 & 80.3 & 26.6 & 21.1 \\
\hline 623 & 2.5 & 0.67 & 011 & 65.0 & 19.1 & 4.5 \\
\hline 623 & 2.5 & 0.80 & 012 & 45.3 & 5.2 & 1.1 \\
\hline 623 & 4.0 & 0.54 & 020 & 77.4 & 23.5 & 16.7 \\
\hline 623 & 4.0 & 0.67 & 021 & 51.2 & 15.6 & 8.4 \\
\hline 623 & 4.0 & 0.80 & 022 & 28.3 & 3.8 & 1.7 \\
\hline 673 & 1.0 & 0.54 & 100 & 96.9 & 20.5 & 16.0 \\
\hline 673 & 1.0 & 0.67 & 101 & 82.2 & 22.0 & 3.5 \\
\hline 673 & 1.0 & 0.80 & 102 & 61.0 & 13.7 & 2.5 \\
\hline 673 & 2.5 & 0.54 & 110 & 89.6 & 25.6 & 21.9 \\
\hline 673 & 2.5 & 0.67 & 111 & 76.6 & 19.6 & 4.7 \\
\hline 673 & 2.5 & 0.80 & 112 & 51.0 & 13.0 & 2.5 \\
\hline 673 & 4.0 & 0.54 & 120 & 78.7 & 17.3 & 13.2 \\
\hline 673 & 4.0 & 0.67 & 121 & 64.0 & 16.4 & 4.3 \\
\hline 673 & 4.0 & 0.80 & 122 & 29.6 & 4.3 & 1.0 \\
\hline 723 & 1.0 & 0.54 & 200 & 97.2 & 24.2 & 18.2 \\
\hline 723 & 1.0 & 0.67 & 201 & 95.7 & 18.4 & 6.6 \\
\hline 723 & 1.0 & 0.80 & 202 & 93.2 & 17.5 & 5.2 \\
\hline 723 & 2.5 & 0.54 & 210 & 91.6 & 22.9 & 17.2 \\
\hline 723 & 2.5 & 0.67 & 211 & 88.2 & 26.3 & 5.7 \\
\hline 723 & 2.5 & 0.80 & 212 & 70.7 & 14.3 & 5.1 \\
\hline 723 & 4.0 & 0.54 & 220 & 86.0 & 24.4 & 20.3 \\
\hline 723 & 4.0 & 0.67 & 221 & 77.2 & 16.3 & 9.1 \\
\hline 723 & 4.0 & 0.80 & 222 & 57.6 & 11.7 & 1.8 \\
\hline \multicolumn{7}{|c|}{ Repeated trials } \\
\hline 673 & 2.5 & 0.67 & 111 & 75.0 & 21.0 & 4.8 \\
\hline 673 & 2.5 & 0.67 & 111 & 73.0 & 20.5 & 5.2 \\
\hline 673 & 2.5 & 0.67 & 111 & 76.5 & 19.6 & 4.7 \\
\hline 673 & 2.5 & 0.67 & 111 & 72.5 & 18.0 & 5.5 \\
\hline 673 & 2.5 & 0.67 & 111 & 73.0 & 18.6 & 5.1 \\
\hline
\end{tabular}

The response surface methodology was used to predict the optimum values of the variables in the range studied. The maximum values of the responses obtained from statistical quadratic equations were plotted in three-dimensional graphs against reaction temperature ( $\mathrm{T}$ ) and weight hourly space velocity (WHSV) for each zeolite catalyst. The three zeolites gave different response surface plots of conversion, yield of hydrocarbons in gasoline boiling range and yield of BTX aromatics. Figures 4, 5 and 6 show the response surface plots for conversion, yield of hydrocarbons in gasoline boiling range and yield of BTX aromatics using HZSM-5 catalyst respectively. The maximum values of the responses were obtained from the statistical quadratic model.

$$
\begin{aligned}
& \mathrm{P}_{\mathrm{C}}=-2923.4+10.48 \mathrm{x}-241.65 \mathrm{y}+5328.62 \mathrm{z} \\
& 8.905 \mathrm{e}-3 \mathrm{x}^{2}+6.29 \mathrm{y}^{2}+628.1 \mathrm{z}^{2} \mathrm{y} \\
& +0.43 \mathrm{x}-18.76 \mathrm{xz}+230.8 \mathrm{yz}-1.6 \mathrm{e} \\
& -4 x^{2} z-3.111 e-3 x y^{2}-1.24 x z^{2} \\
& -6.64 y^{2} z-24.6 y z^{2}-0.27 x y z \\
& Y_{G}=1818.97-5.53 x+73.57 y-2155.6 z \\
& +4.124 \mathrm{e}-3 \mathrm{x}^{2}+6.29 \mathrm{y}^{2}+628.14 \mathrm{z}^{2} \\
& -0.3 x y-7.86 x z+43.29 y z+3.111 e-4 x^{2} \\
& -6.487 \text { e }-3 x^{2} z-778 e-3 x y^{2}+1.15 x z^{2} \\
& +1.51 \mathrm{y}^{2} \mathrm{z}+5.59 \mathrm{yz}^{2}-0.094 \mathrm{xyz} \\
& \mathrm{Y}_{\mathrm{A}}=2279.73-4.89 \mathrm{x}-115.2 \mathrm{y} \\
& -3890.42 z+2.889 \mathrm{e}-3 \mathrm{x}^{2}-0.92 \mathrm{y}^{2} \\
& +1367.12 z^{2}+0.074 x y+6.84 x z \\
& +270.34 y z+5.111 e-5 x^{2} y-3.385 e-3 x^{2} z \\
& -6.667 e-4 x y^{2}-1.18 x z^{2}+1.71 y^{2} z \\
& -107.82 y z^{2}-0.2 x y z
\end{aligned}
$$

\begin{tabular}{|c|c|c|c|c|}
\hline $\begin{array}{l}\text { Source of } \\
\text { variance }\end{array}$ & $\begin{array}{l}\text { Sum of } \\
\text { squares }\end{array}$ & $\begin{array}{l}\text { Degree of } \\
\text { freedom }\end{array}$ & $\begin{array}{c}\text { Mean } \\
\text { square }\end{array}$ & $F$-value \\
\hline \multicolumn{5}{|l|}{$P_{C}$} \\
\hline Mean & $\begin{array}{c}1.71 \times \\
10^{5}\end{array}$ & 1 & $1.71 \times 10^{5}$ & \\
\hline Linear & 9405 & 3 & 3135 & $298.6^{5.42}$ \\
\hline Quadratic & 876 & 6 & 146 & $13.9^{4.32}$ \\
\hline Cubic & 192 & 7 & 27 & $2.6^{4.14}$ \\
\hline Model & 10472 & 16 & 655 & 62.4 \\
\hline Residual & 158 & 15 & 10.5 & \\
\hline Lack of Fit & 141 & 10 & 14.1 & $4.1^{10.05}$ \\
\hline Experimental & 17 & 5 & 3.4 & \\
\hline \multicolumn{5}{|l|}{ Error } \\
\hline \multicolumn{5}{|l|}{$Y_{G}$} \\
\hline Mean & 10422 & 1 & 10422 & \\
\hline Linear & 960 & 3 & 320 & $61.5^{5.42}$ \\
\hline Quadratic & 201 & 6 & 33 & $6.3^{4.32}$ \\
\hline Cubic & 39 & 7 & 5.6 & $1.0^{4.14}$ \\
\hline Model & 1199 & 16 & 75 & 14.4 \\
\hline Residual & 78 & 15 & 5.2 & \\
\hline Lack of Fit & 71 & 10 & 7.1 & $5.9^{10.05}$ \\
\hline Experimental & 6 & 5 & 1.2 & \\
\hline \multicolumn{5}{|l|}{ Error } \\
\hline \multicolumn{5}{|l|}{$Y_{A}$} \\
\hline Mean & 2283 & 1 & 2283 & \\
\hline Linear & 1230 & 3 & 410 & $108^{5.42}$ \\
\hline Quadratic & 285 & 6 & 47.5 & $12.5^{4.32}$ \\
\hline Cubic & 70 & 7 & 10 & $2.6^{4.14}$ \\
\hline Model & 1583 & 16 & 99 & 26 \\
\hline Residual & 57 & 15 & 3.8 & \\
\hline Lack of Fit & 57 & 10 & 5.7 & $57^{10.05}$ \\
\hline
\end{tabular}

where $x$ is the temperature; $y$ is the weight hourly space velocity and $z$ is the catalyst pore size.

Table 9: Analysis of variance (ANOVA) for the three responses conversion, yield of gasoline and aromatics yield using the nonlinear model 


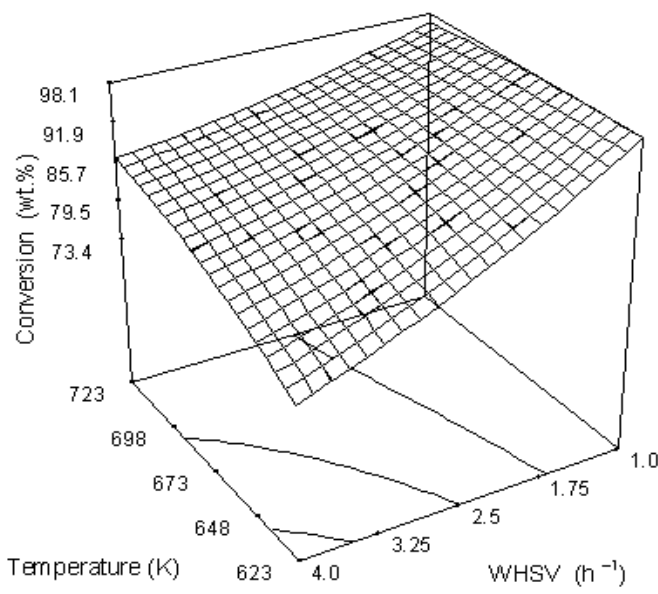

Fig. 4: Response surface plot for conversion of palm oil obtained from the nonlinear model over HZSM-5 catalyst.

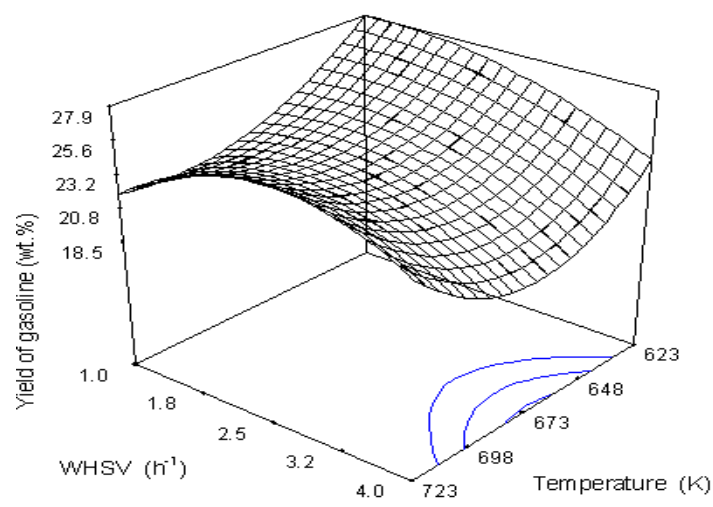

Fig. 5: Response surface plot for yield of gasoline obtained from the nonlinear model over HZSM-5 catalyst.

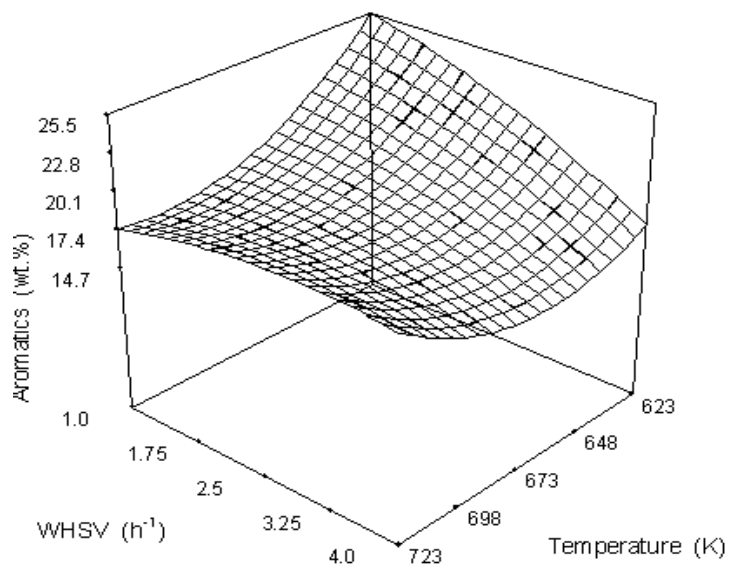

Fig. 6: Response surface plot for yield of aromatics obtained from the nonlinear model over HZSM-5 catalyst.
The optimum values obtained from the statistical model were:

- For HZSM-5 catalyst, the optimum yield of gasoline was $28.1 \mathrm{wt} . \%$ at WHSV of $1.75 \mathrm{~h}^{-1}$ and temperature $623 \mathrm{~K}$ with a conversion of 91.3 wt.\%. The optimum yield of BTX aromatics was 25.5 wt. $\%$ at temperature $623 \mathrm{~K}$ and WHSV 1.0 $\mathrm{h}^{-1}$ with conversion $95.0 \mathrm{wt} . \%$.

- For zeolite $\beta$ catalyst, the optimum yield of gasoline was 23.9 wt.\% at temperature $723 \mathrm{~K}$, $1.75 \mathrm{~h}^{-1}$ WHSV at conversion $93.6 \mathrm{wt} \%$. The optimum yield of BTX aromatics was $7.3 \mathrm{wt} . \%$ with conversion of 98.5 wt. $\%$ at $723 \mathrm{~K}$ and WHSV of $1 \mathrm{~h}^{-1}$.

- For USY zeolite catalyst, the optimum gasoline yield was 16.9 wt. \% and yield of BTX aromatics $7.3 \mathrm{wt} . \%$ at conversion of $85.7 \mathrm{wt} . \%$ at $723 \mathrm{~K}$ and WHSV of $1 \mathrm{~h}^{-1}$.

\section{CONCLUSIONS}

- $\quad$ The medium pore size zeolite catalyst (HZSM-5) with the lowest acidity, gave the best performance among the three zeolite catalysts tested in terms of conversion, yield of gasoline and yield of BTX aromatics.

- Type of palm oil feed did not affect the conversion or the production of gasoline.

- The optimum values of reaction parameters were obtained using Design Of Experiment (DOE) coupled with Response Surface Methodology (RSM).

- The experimental values of the conversion, yield of gasoline and yield of BTX aromatics were in good agreement with the values obtained from the proposed model.

\section{ACKNOWLEDGEMENT}

The financial support by the Ministry of Science, Technology \& Environment, Malaysian Govt. under long term IRPA grant (Project: 03-02-05-7005) is gratefully acknowledged.

\section{REFERENCES}

[1] S.P.R Katikaneni,. J.D. Adjaye, R.O. Idem and N.N. Bakhshi, "Catalytic Conversion of Canola Oil over Potassium-Impregnated HZSM-5 Catalysts: $\mathrm{C}_{2}-\mathrm{C}_{4}$ Olefin Production and Model Reaction Studies", Ind. Eng. Chem. Res. 35, pp 3332 -3346 1996.

[2] R.O. Idem, S.P.R. Katikaneni and N.N. Bakhshi, "Catalytic Conversion of Canola Oil to Fuels and Chemicals: Roles of Catalyst Acidity, Basicity, and Shape Selectivity on Product Distribution", Fuel Proc. Tech. 51, pp 101-125, 1997.

[3] S. Bhatia, H.J. Kee, L.M. Lan and A.R. Mohamed, "Production of Biofuel by Catalytic Cracking of Palm Oil: Performance of Different Catalysts", Proc. Biofuel, PORIM Intl. Biofuel and Lubricant Conf, Kuala Lumpur, pp 107-112, 1998. 
[4] S.P.R. Katikaneni, J.D. Adjaye and N.N. Bakhshi, "Performance of Aluminophosphate Molecular Sieve Catalysts for Production of Hydrocarbons from WoodDerived and Vegetable Oils", Energy \& Fuels. 9, pp 1065-1078, 1995.

[5] Y.S. Prasad, N.N. Bakhshi, J.F. Mathews and R.L. Eager, "Catalytic Conversion of Canola Oil to Fuels and Chemical Feedstocks. Part I: Effect of Process Conditions of the Performance of HZSM-5 Catalyst". Can. J. Chem. Eng. 64, pp 278-284, 1986.

[6] S. Bhatia, "Zeolite Catalysis Principles and Applications", CRC Press Inc Boca Raton, FL, USA, 1990.

[7] J.D. Adjaye, S.P.R. Katikaneni, and N.N. Bakhshi, "Catalytic Conversion of A Biofuel to Hydrocarbons: Effect of Mixtures of HZSM-5 and Silica-Alumina Catalysts on Product Distribution”, Fuel Proc. Tech. 48, pp 115-143, 1995.

[8] T.Y. Leng, A.R. Mohamed and S. Bhatia, "Production of Fuels from Catalytic Conversion of Palm Oil: Preliminary Studies", Proc. Reg. Symp. Chem. Eng. 1, pp 75-81, 1997.

[9] H. Gonzalez, A. Rodriguez, L. Cendeno, J. Ramirez and J. Aracil, "Isomerization of $\mathrm{C}_{8}$ Aromatics over a Pt/Mordenite Catalyst: A statistical Model", Ind. Eng. Chem. Res. 35, pp 3964-3972, 1996.

[10] B. Ghosh, D.C. Agrawal and S. Bhatia, "Synthesis of Zeolite A from Calcined Diatomaceous Clay: Optimization Studies", Ind. Eng. Chem. Res. 33, pp 2107-2110, 1994.

[11] G.E.P. Box, W.G. Hunter and J.S. Hunter, Statistics for Experimenters: An Introduction to Design, Data Analysis, and Model Building, John Wiley \& Sons, New York, NY, USA, 1978.

[12] W.G. Cochran and G.M. Cox, Experimental Designs, $2^{\text {nd }}$ edn., John Wiley \& Sons: Singapore, 1957.

[13] N. Sanchez, M. Martinez, and J. Aracil, "Selective Esterification of Glycerine to 1. Glycerol Monooleate 2. Optimization Studies", Ind. Eng. Chem. Res. 36, pp 1529-1534, 1997.

[14] T.S. Tang, C.L. Chong, M.S.A. Yusoff and M.T. AbGapor, "Characteristics of Superolein from the Fraction of Palm Oil”, PORIM Technology Bulletin, 17, 1995.

[15]D.C. Montgomery, Design and Analysis of Experiments, $3^{\text {rd }}$ edn., John Wiley \& Sons, New York, NY, USA, 1991.

[16] J. Abbot, and P.R. Dunstan, "Catalytic Cracking of Linear Paraffins: Effects of Chain Length", Ind. Eng. Chem. Res. 36, pp 76 - 82, 1997.

[17] J.M Arandes, I. Abajo, I Fernandez, M.J. Azkoiti and J. Bilbao, 'Effect of HZSM-5 Zeolite Addition to Fluid Catalytic Cracking Catalyst. Study in a Laboratory Reactor Operating under Industrial Conditions. Ind. Eng. Chem. Res., 39, pp 1917 - 1924, 2000.

\section{List of Symbols}
A factor code of temperature
B factor code of WHSV
C factor code of catalyst pore size
CPS catalyst pore size (nm)
D factor code of number of carbon atoms

$F$-value the ratio of model mean square to the appropriate error mean square

NCA number of carbon atoms

$P_{C} \quad$ conversion of palm oil (wt.\%)

$\mathrm{T} \quad$ temperature $(\mathrm{K})$

USY ultrastable Y zeolite

WHSV weight hourly space velocity $\left(\mathrm{h}^{-1}\right)$

$x \quad$ actual temperature $(\mathrm{K})$

$y \quad$ actual weight hourly space velocity $\left(\mathrm{h}^{-1}\right)$

$Y_{A} \quad$ yield of BTX aromatic hydrocarbons (wt.\%)

$Y_{G} \quad$ yield of hydrocarbons in gasoline boiling range (wt.\%)

$z \quad$ actual catalyst pore size $(\mathrm{nm})$

\section{BIOGRAPHIES}

Farouq Twaiq received his B. Sc. degree in Chemical Engineering from Amman University College for Applied Engineering, Amman, Jordan, 1994. He worked as supervisor engineer in Al-Ryadh Company for vegetable oil industries, 1994-1996. He received his M.Sc. degree in 1998 and currently he is a Ph.D. student in the School of Chemical Engineering at Universiti Sains Malaysia under supervision of Prof. S. Bhatia. His research interests are in the synthesis and characterization of zeolite and molecular sieve composite materials and their applications as cracking catalysts.

Prof. Subhash Bhatia joined the School of Chemical Engineering, Universiti Sains Malaysia, Perak Branch Campus, in 1995. He was a full Professor at the Department of Chemical Engineering, Indian Institute of Technology, Kanpur (India). Prof. Bhatia was visiting faculty at the University of Qeensland, Australia from 1988 - 1989 and 1994 - 1995. His research interests are zeolite catalysis, chemical reaction engineering and environmental catalysis. He has written a book on Zeolite Catalysis that was published by CRC Press, USA and has published more than 75 papers in national and international journals.

Dr. Noor Asmawati binti Mohd. Zabidi received her BS. in chemistry from Nebraska Wesleyan University, Lincoln, USA in 1986. She carried out research in photocatalysis under supervision of Prof. Timothy F. Thomas at University of Missouri-Kansas City, USA where she received her Ph.D. in 1995. She has been a lecturer at School of Chemical Engineering, Universiti Sains Malaysia, Perak Branch Campus from 19962000. At present, she is a lecturer at Universiti Teknologi Petronas, Tronoh, Perak. 
IIUM Engineering Journal, Vol. 2, No. 1, 2001 